\title{
Cambios en la situación de la vejez en el siglo XX
}

\author{
Antonio Ordóñez Plaja
}

En forma breve, esquemática a veces y con inevitables generalizaciones, pretendo presentar a ustedes una película verbal de lo que han sido los cambios a los que ha estado sometido el viejo en este siglo.

Creo que aun cuando esta es mi visión y, por tanto, inevitablemente tendrá algo de subjetividad, ésta estará bien equilibrada por varios estudios y dos bancos de datos que realicé con excelentes colaboradores durante la década de los 80 .

Hago esta acotación siguiendo el consejo de Gunnar Myrdal quien insiste en que la investigación social siempre tendrá algo de subjetivo y que es más honrado declararlo desde el inicio. En las primeras décadas del siglo $X X$, el viejo no era un problema para el gobierno ni para la sociedad. Era, si acaso, un problema para la familia, familia extensa, con casa de tres patios en las ciudades (Bogotá tenía unos 200.000 habitantes) y, en el campo, el espacio era extenso, en la casa y en los alrededores. El hombre mayor era el paterfamilias y, con frecuencia, abusaba de la autoridad que le confería su status. La mujer, dedicada a las labores del hogar como era imperativo en esa época, generalmente atenuaba la severidad del abuelo.

El viejo podía ser un problema para la familia, por lo anotado, pero nada más. El viejo en el área rural, más o menos el $80 \%$ de la población, era necesario y se le respetaba porque hacía las veces de notario, juez y consejero, etc. Era él quien aclaraba los pleitos por límites de terrenos por cuanto era quien recordaba cómo se había realizado el negocio muchos años antes y casi siempre de palabra. En asuntos sociales, él era quien decidía si un matrimonio era deseable o no, sin dar explicaciones pues la comunidad partía de la premisa implícita de que sus recuerdos de años que los jóvenes y los adultos no conocieron, le hacían sabedor de taras, parentescos desconocidos, etc. Su status era bien definido, era respetado y hasta querido en general.

La mujer anciana, más sumisa aún que la urbana, repartía su tiempo entre el hogar, el cultivo de la tierra y el cuidado de los animales y sólo descansaba con la muerte.

La salud en esa época era tan precaria como lo es hoy día la seguridad personal. El crecimiento demográfico era lento lo mismo que la migración rural-urbana. La única vacuna existente era la de viruela y no llegaba a todo el mundo. Al caminar por la Carrera Séptima, camino consuetudinario, era inevitable cruzarse con un ataúd blanco, pequeño, cargado por cuatro personas con ruana y alpargatas o con el pie en el suelo. A veces, había entierros elegantes. Los niños morían como moscas de enfermedades hoy día prevenibles. Los adultos no siempre resistían la tifoidea, la neumonía, la tuberculosis, la fiebre puerperal, la sepsis en general.

Solamente a mediados de siglo, con la aparición de las sulfanilamidas y unos años después la penicilina, el cuadro cambia radicalmente; van apareciendo vacunas efectivas y se trata de llegar con ellas al mayor número de niños.

La morbimortalidad decrece rápidamente. Aparece la violencia y se queda definitivamente en distintas formas y por diferentes razones.

Investigador emérito, Instituto Nacional de Salud, Santa Fe de Bogotá, D.C., Colombia 
Como consecuencia, la migración rural-urbana que ya se había iniciado por razón de mayores oportunidades reales o imaginarias en trabajo, educación y salud, se acelera pues a los factores de atracción de las zonas urbanas se agregan los factores de expulsión en el área rural.

Las ciudades crecen en forma desordenada, sin recursos para atender las necesidades básicas de los inmigrantes. Comienzan a aparecer los tugurios.

La asistencia pública y la seguridad social se materializan tal como lo había recomendado Rafael Uribe Uribe desde 1912.

Las condiciones socioeconómicas cambian y la estructura familiar comienza a transformarse.

La familia extensa es reemplazada por la familia nuclear con lo cual el viejo va quedando en una situación ambigua. En una sociedad cada vez más entregada al consumismo y donde el dinero reemplaza valores tradicionales, el viejo empieza a ser visto como un costo y un estorbo, inclusive el jubilado que aporta al hogar ha perdido durante los años de trabajo un espacio en el hogar y las horas que pasa en la casa trastornan la marcha de la rutina de más de veinte años. Los hijos, con mayor educación que él, comienzan a verlo como alguien que, en el campo intelectual, no tiene nada que aportar. La autoestima del anciano declina.

\section{¡Paterfamilias ha muerto!}

Pero el viejo no, sigue vivo aunque cada día más aislado y solo, tanto si está físicamente separado como si convive con algún familiar.

Por otra parte, el despertar de la mujer, su ingreso masivo a la universidad y a la fuerza laboral va a duplicar la materia gris productiva y a darle una nueva estructura a la sociedad. Una sociedad que desde la Colonia era irrevocablemente machista, racista y clasista, comienza a mejorar de estos horribles males sin lograr erradicarlos todavía.

La atención del anciano por parte del Estado, lo mismo que la invalidez, no es el resultado de una política, como sí lo ha sido por parte de la Iglesia que aún hoy día hace lo posible en toda parroquia y como una clara posición dentro de las actividades de la pastoral social.

La atención por parte del Estado ha sido un tanto coyuntural y a veces espasmódica. Por ejemplo, en la época de la Independencia se crean los montepíos militares para proteger a las familias de quienes fallecieron en la guerra y a los inválidos. Pero, los montepíos creados en 1827 desaparecen para volver a existir por la Ley 9 de $1843 \mathrm{y}$, luego de varias reformas, desaparecen nuevamente por la Ley 30 de 1855. En 1890, vuelven a crearse por la Ley 96 . Sus bases son las mismas de los iniciales y con el tiempo se va mejorando el sistema en cuanto a administración, organización y servicios.

Para terminar con esta retrospectiva del siglo XIX, se debe mencionar que en 1886 la Ley 50 fija las condiciones para la concesión de pensiones a los empleados civiles que hayan trabajado 20 años como mínimo y "que hayan trabajado con inteligencia y pureza, que comprueben con documentos auténticos sus servicios y que no hayan sufrido alcances o remoción por mal manejo, incuria u omisión".

Esta ley, que es el principio de la previsión social, va seguida -ya en el siglo XX-por otras que modifican las pensiones de los profesores y maestros.

En 1905, se promulga la Ley 29 con algunas características de humor negro al aumentar a 30 los años de servicio y a 60 la edad de jubilación en una época en la cual la esperanza de vida promedio era inferior a 60 años.

En 1915, nace la Ley 57 en homenaje a la memoria de Rafael Uribe Uribe; es el inicio de nuestro derecho laboral y de la previsión social, al definir los accidentes de trabajo como algo que debía afrontar el empleador.

Uribe Uribe creía en el Estado bienhechor y en su obligación de proveer a las necesidades de los ancianos caídos en la pobreza y sin fuerza para trabajar. Señaló, también, la necesidad de un código de trabajo, "la previsión y la ayuda social mutua".

En los años 1944 y 1946, se crean las Cajas de Previsión Social para el sector público y el 
Instituto Colombiano del Seguro Social. Todo esto coincide con una época de agitación social.

En cuanto a medidas especiales para proteger a la ancianidad desvalida, se expide la Ley 29 en 1975 que busca darle al anciano indigente, albergue, servicios de salud, terapia ocupacional y recreación, y para ello crea un fondo especial. Infortunadamente, este fondo nunca recibe aporte alguno como lo ordena la misma ley.

En desarrollo de esta ley que otorga facultades extraordinarias al gobierno, se crea el Consejo Nacional de Protección al Anciano conformado por las más altas personalidades. Hasta 1989, es decir 15 años después, el consejo no se había reunido y es probable que la gente y los altos poderes ni siquiera supieran de su existencia.

La preocupación oficial por el anciano desvalido es evidente a nivel verbal, pero a la hora de convertir tan buenas intenciones en realidades, nadie aparece.

En la década de los ochenta y como consecuencia de las normas de descentralización, se le fijan obligaciones a los departamentos y municipios en relación con los ancianos y colaboración técnica, nutricional y económica del ICBF "si su situación financiera lo permite".

Es evidente que sólo se han mencionado algunas de las normas que protegen al anciano, particularmente en el campo laboral, pero existen, además, multitud de normas en el código civil sobre la obligatoriedad de ver por los ancianos por parte de los parientes, en primer lugar, los hijos y los hermanos incluidos los de simple conjunción (hermanos medios). También, hay normas en el código penal que sancionan el incumplimiento con prisión de 6 meses a 3 años. Lo más importante de lo anterior es la obligación alimentaria así llamada aunque cobija no sólo la obligación de darle comida sino alojamiento, vestuario y atención médica.
Infortunadamente, son normas poco conocidas y rara vez aplicadas, probablemente porque no existe una defensoría del anciano similar a la defensoría del menor.

Con el aumento rápido del número de ancianos, es probable que en el futuro exista un mecanismo sencillo que le permita al viejo pobre o indigente reclamar sus derechos. El abandono, el rechazo y la hostilidad hacia el viejo por parte de los descendientes o el cónyuge pueden llegar a configurar una conducta delictiva. La negación del afecto así como la amenaza física o las humillaciones permanentes, pueden configurar delito de tortura moral penado con prisión de 1 a 3 años.

Deliberadamente, me he abstenido de referirme a los últimos 10 o 15 años por varias razones: 1) porque estamos en un período de cambios y ajustes dentro de un contexto de crisis no sólo económica, que hace difícil ser objetivo;2) porque ustedes han vivido y diría que han sufrido la situación presente y estoy seguro que la conocen mejor que yo.

Lo único claro es que el presente y el próximo futuro del anciano no se muestran promisorios a nivel mundial y menos en Colombia. Les quiero dejar como tema de meditación la posible unión de más de 2 millones de ancianos y unos 3 millones que están haciendo cola para serlo. Un grupo de presión de esa magnitud podría lograr que no se deteriore lo presente y que la situación de los pobres e indigentes se alivie con su criterio de solidaridad social.

A pesar de haber mencionado solamente unos pocos aspectos jurídicos por considerarlo importante y pertinente, espero haber despertado en ustedes un interés por la situación del anciano y recordarles que algún día lo serán -eso esperoporque la alternativa es peor.

Discurso pronunciado en el IX Congreso de la Asociación de Exalumnos de Medicina de la Universidad Nacional, Premio a la Excelencia en Medicina Colombiana. Santa Fe de Bogotá, D.C., 27 de agosto de 1999 